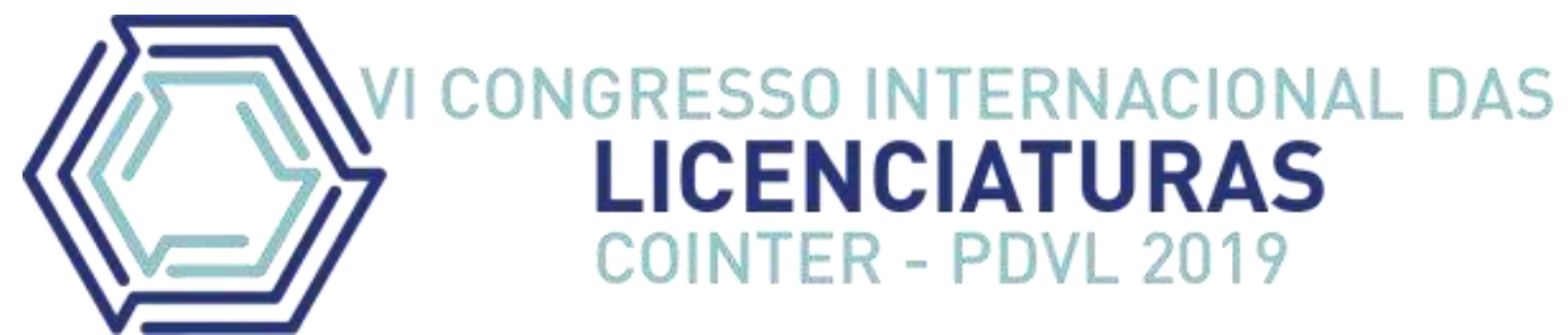

\title{
O USO DO GEOGEBRA NO ENSINO DE FUNÇÕES TRIGONOMÉTRICAS NA $2^{\mathrm{a}}$ SÉRIE DO ENSINO MÉDIO
}

\author{
EL USO DE GEOGEBRA EN LA ENSEÑANZA DE FUNCIONES \\ TRIGONOMÉTRICAS EN EL SEGUNDO GRADO DE LA ESCUELA \\ SECUNDARIA.
}

\section{THE USE OF GEOGEBRA IN TEACHING TRIGONOMETRIC FUNCTIONS IN THE 2ND GRADE OF HIGH SCHOOL}

\author{
Apresentação: Comunicação Oral
}

Antonio Lucas Alves de Sousa ${ }^{1}$; Bruno Oliveira de Sousa ${ }^{2}$

DOI: https://doi.org/10.31692/2358-9728.VICOINTERPDVL.2019.0021

\begin{abstract}
Resumo
Sabe-se que a educação, propriamente dita, deve alcançar certos objetivos, que uma aula tradicional muitas vezes é insuficiente, o que muitas vezes é porque o professor não consegue prender a atenção dos alunos. Sabendo disso, uma das formas de se chamar atenção deles é justamente apresentar a aplicabilidade de certo conhecimento no cotidiano do aluno, usando a interdisciplinaridade. O Geogebra possui ferramentas para a construção de gráficos de funções que são de difícil visualização, a menos que se tenha uma ferramenta semelhante ao Geogebra ou o próprio. $\mathrm{O}$ fato é que na $2^{\mathrm{a}}$ série do ensino médio os alunos se aprofundam nos cálculos de funções trigonométricas, vem surgir novas funções e alguns se sentem perdidos, acham complicado demais de se entender e visualizar. Mostrar como a versatilidade do Geogebra pode ser usada a favor dos professores para que essa suavização do ensino de matemática seja possível, é o objetivo principal deste artigo. Mostrar como a versatilidade do Geogebra ajuda, se as tecnologias dentro de sala facilitam ou dificultam a ensino aprendizagem, e como o Geogebra pode ajudar no ensino de funções trigonométricas. Analisar a compreensão dos com relação às funções trigonométricas, e ver o quão benéfico é usar uma tecnologia, no caso o Geogebra em favor do ensino da matemática. Além disso, inferir também que as tecnologias quando bem usadas em sala de aula, podem ser uma peça fundamental para um melhor ensino aprendizagem, e relatar as experiências adquiridas dos alunos após terem tido contato com o Geogebra, e seu uso no ensino de funções trigonométricas. Esta pesquisa está baseada em pesquisas feitas anteriormente por Moran (2013), D’Ambrósio (1993) e Silva (2018). E podese concluir que as tecnologias influenciam grandemente no ensino da matemática, a saber, o Geogebra é uma excelente ferramenta, que instigou os alunos a ter até mesmo interesse por matemática.
\end{abstract}

\footnotetext{
${ }^{1}$ Licenciatura em matemática, Instituto Federal de Educação, Ciência e Tecnologia (IFPI) campus Angical, antonluc8912@gmail.com

${ }^{2}$ Mestre em matemática, PROFMAT-UFPI, bruno_bos@ifpi.edu.br
} 
Palavras-Chave: Geogebra, Matemática, Funções trigonométricas.

\title{
Resumen
}

Es bien sabido que la educación en sí misma debe alcanzar ciertos objetivos, que una clase tradicional a menudo es insuficiente, lo que a menudo se debe a que el maestro no puede llamar la atención de los estudiantes. Sabiendo esto, una de las formas de llamar su atención es precisamente presentar la aplicabilidad de ciertos conocimientos en la vida diaria del alumno, utilizando la interdisciplinariedad. Geogebra tiene herramientas para construir gráficos de funciones que son difíciles de ver a menos que tenga una herramienta similar a Geogebra o en sí misma. El hecho es que, en el segundo grado de la escuela secundaria, los estudiantes profundizan en los cálculos de las funciones trigonométricas, vienen nuevas funciones y algunos se sienten perdidos, les resulta demasiado complicado de entender y visualizar. El objetivo principal de este artículo es mostrar cómo la versatilidad de Geogebra se puede utilizar en favor de los maestros para hacer posible esta suavización de la enseñanza de las matemáticas. Muestre cómo ayuda la versatilidad de Geogebra, si las tecnologías en la habitación hacen que el aprendizaje de la enseñanza sea más fácil o difícil, y cómo Geogebra puede ayudar a enseñar las funciones trigonométricas. Analice su comprensión de las funciones trigonométricas y vea cuán beneficioso es usar una tecnología, en este caso Geogebra a favor de la enseñanza de las matemáticas. Además, también se puede inferir que las tecnologías, cuando se usan bien en el aula, pueden ser una piedra angular para una mejor enseñanza y aprendizaje, e informar sobre las experiencias de los estudiantes, obtenidas del contacto con Geogebra y su uso en la enseñanza de funciones trigonométricas. Esta investigación se basa en investigaciones anteriores de Moran (2013), D'Ambrósio (1993) y Silva (2018). Y se puede concluir que las tecnologías influyen en gran medida en la enseñanza de las matemáticas, a saber, Geogebra es una herramienta excelente que ha llevado a los estudiantes a interesarse incluso en las matemáticas.

Palabras Clave: Geogebra, Matemáticas, Funciones Trigonométricas.

\begin{abstract}
It is well known that education itself must achieve certain objectives, that a traditional class is often insufficient, which is often because the teacher cannot hold students' attention. Knowing this, one of the ways to draw their attention is precisely to present the applicability of certain knowledge in the student's daily life, using interdisciplinarity. Geogebra has tools for constructing function graphs that are difficult to see unless you have a tool similar to Geogebra or itself. The fact is that in the second grade of high school students deepen in calculations of trigonometric functions, come new functions and some feel lost, find it too complicated to understand and visualize. Showing how Geogebra's versatility can be used in favor of teachers to make this smoothing of mathematics teaching possible is the main purpose of this paper. Show how Geogebra's versatility helps, whether in-room technologies make teaching learning easier or harder, and how Geogebra can help in teaching trig functions. Analyze their understanding of trigonometric functions, and see how beneficial it is to use a technology, in this case Geogebra in favor of teaching mathematics. In addition, it can also be inferred that technologies, when well used in the classroom, can be a cornerstone for better teaching and learning, and report on students' experiences
\end{abstract}


gained from contact with Geogebra, and their use in teaching trigonometric functions. This research is based on previous research by Moran (2013), D'Ambrósio (1993) and Silva (2018). And it can be concluded that technologies greatly influence the teaching of mathematics, namely, Geogebra is an excellent tool that has prompted students to even have an interest in mathematics.

Keywords: Geogebra, Mathematics, Trigonometric functions.

\section{Introdução}

Um dos grandes problemas enfrentados no ensino de funções trigonométricas é o fato de que se trata de um conhecimento complexo da matemática, com uma linguagem própria e abstrata, com suas peculiaridades e que alguns alunos demoram a compreender. Porém o fato é que não há apenas uma explicação para que exista essa dificuldade, e segundo Oliveira (2006, p. 11), um dos fatores marcantes é o excesso de formalismo e a formalização precoce que "impede o aluno de compreender significativamente os conceitos ou utilizá-los em outros contextos". Esse formalismo usado pelo professor acaba que por dificultar para alguns alunos, e pode ser o grande causador da não compreensão do mesmo. Então o professor deve se ater a tal ponto, no sentido de que ele deve buscar meios que facilitem o ensino da matemática, que em questão as funções trigonométricas.

O fato é que deve haver uma mudança no modelo tradicional de aula, o mesmo deveria já ser considerado pelos professores como algo ultrapassado, e os mesmos deveriam criar metodologias diferenciadas, os professores devem propor aulas diferenciadas que incentivem o aluno a participar da aula, criando um ambiente onde

A mudança do modelo de aula tradicional - nas quais os alunos ficam todos inquietos, copiando e fazendo longas listas de exercícios repetitivos - para uma aula em que eles buscam inquietamente solucionar problemas e fazer descobertas representa um grande contraste. (OLIVEIRA, 2006, p.42)

As funções trigonométricas estão presentes em diversas áreas, como a física já mencionada, geografia, arquitetura e engenharia, em se tratando de interdisciplinaridade "não se pretende a construção de uma superciência, mas uma mudança de atitude frente ao problema do conhecimento, uma substituição da concepção fragmentária para a unitária do ser humano.” (FAZENDA, 2002 apud ALVES, 2010, p. 62).

Uma das formas de diferenciar a aula é a utilização do software Geogebra que surge como um meio facilitador do ensino de geometria e de funções, onde o professor tem 
autonomias para criar funções, quer sejam do $1^{\circ}$ ou $2^{\circ}$ grau, como as exponenciais, logarítmicas e as trigonométricas, além da parte voltada para a geometria.

Como a Trigonometria é um ramo da matemática que envolve não só o estudo de triângulos, mas apresenta também várias aplicações em diversas áreas do conhecimento, como já mencionadas algumas, como física e engenharia, que podem ser modeladas por funções trigonométricas, e os recursos que Geogebra possui possibilita a construção de gráficos de funções que podem contribuir para a exploração dos conceitos de uma forma mais abrangente, permitindo a validação de descobertas de relações e propriedades.

A trigonometria, em essência está em nosso cotidiano, porém os alunos ainda tendem a ter dificuldades neste conteúdo. Então, como as tecnologias podem ajudar na compreensão e aprendizagem de um conteúdo matemático abstrato como a trigonometria? Pensando nisso, escolheu-se o Geogebra, pela facilidade de acesso, pois ele está disponível para download e também pode ser encontrado online.

Esta pesquisa foi realizada em uma escola, o Educandário Bonus, na cidade de Água branca, com os alunos da $2^{\text {a }}$ série do ensino médio, buscando assim observar as devidas dificuldades dos mesmos quando se trata de trigonometria, e procurando sanar as lacunas das aulas tradicionais, utilizando o Geogebra como meio tecnológico em favor do ensino da matemática. Ela tem por objetivo analisar a compreensão dos alunos com relação às funções trigonométricas, e ver o quão benéfico é usar uma tecnologia, no caso o Geogebra em favor do ensino da matemática. Além disso, inferir também que as tecnologias quando bem usadas em sala de aula, podem ser uma peça fundamental para uma melhor ensino-aprendizagem, e relatar as experiências adquiridas dos alunos após terem tido contato com o Geogebra, e seu uso no ensino de funções trigonométricas.

A hipótese desta pesquisa consiste no princípio de que os meios tecnológicos são eficientes no aprendizado das funções trigonométricas, em particular, o software Geogebra, que possui um aparato de recursos que são de extrema importância no ensino da matemática, e na compreensão visual de certos conceitos são deveras mais abstratos. O que nos instigou a respeito da pesquisa, foi ver que alguns alunos, se não a maioria, saem das escolas sem ter uma noção básica de trigonometria, quer sejam pelas metodologias aplicadas pelo professor, quer seja pela complexidade do conteúdo. O fato é o surgimento das tecnologias vieram para a mudança também da forma de se ensinar, já que a compreensão de certos conteúdos, se fazem 
mais efetivos quando os alunos podem visualizar, tanto a aplicação do mesmo em seu cotidiano como também o que o professor diz.

\section{Fundamentação Teórica}

Hoje em dia todos precisamos usar meios tecnológicos para facilitar a vida social, já que a tecnologia está em tudo, as Tecnologias da informação(TI) podem contribuir para o ensino escolar, onde na perspectiva de Carvalho e Godoy (2012, p. 65) "a inserção de TI no ambiente escolar tem sido vista como um potencializador das ideias de se quebrar a hegemonia das disciplinas e impulsionar a interdisciplinaridade".

Os recursos disponibilizados a partir da tecnologia, como os softwares educacionais, instigam a participação dos alunos, a tomada de decisão, a levantar conjecturas e fazer analogias em um processo de ensino e aprendizagem. Por si só as novas tecnologias, são atrativas, justamente pelo fato de que os jovens alunos estão em contato com as mesmas constantemente.

No quadro, o professor apresenta as dificuldades em mostrar correlações entre as incógnitas e suas correspondências no gráfico, por se tratar de um processo demorado e lento, já que ele tem um nível de abstração grande, e isso por si só já se torna mais complicado para que os alunos compreendam. Com o Geogebra a aula se torna mais dinâmica, o aluno passa a visualizar a matemática em movimento. $\mathrm{O}$ professor debate em torno dos parâmetros ao movimentar o gráfico, e o aluno tem a possibilidade de conceber a essência da matemática. E em se tratando da aplicação da tecnologia o PCN de Matemática relata que:

Quanto aos softwares educacionais é fundamental que o professor aprenda a escolhêlos em função dos objetivos que pretende atingir e de sua própria concepção de conhecimento e de aprendizagem, distinguindo os que se prestam mais a um trabalho dirigido para testar conhecimentos dos que procuram levar o aluno a interagir com o programa de forma a construir conhecimento. (BRASIL, 1997, p. 35)

O Geogebra é uma ferramenta tecnológica que auxilia na construção e visualização de figuras, sólidos e de funções, e possui um leque de opções com relação ao seu uso em sala, sendo o objetivo final, uma melhor ensino-aprendizagem.

As tecnologias por serem algo que estão no meio dos jovens alunos de hoje, acaba por ser um meio atrativo, e do melhor compreensão para os mesmos, Paiva (1997) escreve sobre a Matemática que está no cotidiano do aluno e afirma que é necessário tirar proveito da chegada dos computadores para "resgatar o espírito crítico do jovem, essencial ao aprendizado da ciência Matemática". 
Cabe ressaltar ainda que quando o aluno não vê aplicabilidade daquele conhecimento em seu dia a dia, ou não vê como ele usará tal conhecimento em seu futuro, ele se sente desmotivado a aprender o mesmo, por acreditar que não há aplicabilidade daquele conhecimento. O conteúdo de funções trigonométricas é, em grande parte, abstrato, o que gera uma maior dificuldade de expor aplicações práticas para tais funções. Não obstante, podemos perceber a presença de tais funções nos meios mais inesperados, como na natureza, na forma como estão dispostos os rios, ou movimentos de uma cobra ou de peixe, ou até mesmo em construções feitas pelo ser humano. Sabendo disso, uma das formas de se chamar atenção dos alunos é justamente apresentar a aplicabilidade de certo conhecimento no cotidiano do aluno, usando a interdisciplinaridade. Isso fará com que o mesmo tenha um certo interesse, pois ele verá a necessidade de aprender tal conteúdo, já que o mesmo tem uma aplicabilidade em seu cotidiano, ou terá em seu futuro.

Em sua inserção na Física temos o Movimento Harmônico Simples (MHS), ou o Tsunami, o Big Ben e o processo respiratório. Persicano (2014) trabalha exatamente sobre o MHS, e Delfino(2015) desenvolveu modelagens a respeito Tsunami Sendai, o Big Ben e o processo respiratório, e o que chama atenção é a forma com que esses pesquisadores trabalharam assuntos tão abstratos, usando a matemática e o software Geogebra como suporte no ensino e aprendizagem de conceitos das funções trigonométricas e nas suas devidas aplicabilidades.

Logo essa ferramenta tão importante deve ser levada em consideração com relação a desabstração do conteúdo de funções, sendo um deles, o conteúdo de funções trigonométricas. As tecnologias estão muito presentes em nosso dia a dia como diz Silva $(2018$, p. 3)

Em nosso dia a dia podemos notar facilmente a presença das ferramentas tecnológicas digitais. Elas nos ajudam na comunicação, no trabalho, nos afazeres de casa, nos momentos de lazer e em muitas outras atividades. Hoje, elas são quase indispensáveis para a nossa convivência em sociedade, e na escola não é diferente, necessitamos de máquinas para imprimir e copiar provas, de computadores para a comunicação com as secretarias de educação, e telefones para a comunicação entre professores e diretores. No entanto, quase não notamos essa presença dentro das salas de aulas.

Ainda hoje, mesmo com os avanços tecnológicos há professores que insistem em dar aulas tradicionais e ficar somente nisso, alguns ainda mantém um modelo prático comum, e que não ajuda na compreensão o conteúdo, mas sim em decorar o mesmo.

Foi possível perceber que há muitos docentes que conduzem suas aulas apresentando definições seguidas de listas de exercícios, treinando os alunos para reprodução do conteúdo, 
muitas vezes apenas decorado e não compreendido. Ainda conforme Fiorentini (1995), Miorim (1998), D’Ambrósio (1993), essa prática não é propícia à aprendizagem por não possibilitar a compreensão e a construção do conhecimento pelo aluno. Penso que os professores precisam de atividades de ensino e aprendizagem e de uma postura diferenciada para trabalhar os conteúdos de Trigonometria, de maneira significativa em sala de aula em que os estudantes passam a ser os protagonistas e o professor o orientador/mediador. (CORRADI, p.21, 2013)

O fato é que esse modelo de aula apresenta falhas em sua metodologia a acaba por não alcançar o real objetivo que é a aprendizagem concreta do conhecimento apresentado ao aluno, e que ele desenvolva tal habilidade proposta para a série em que o mesmo está. As instituições de ensino ainda temem as mudanças e segundo Moran (2013, p. 57) "as tecnologias digitais móveis desafiam as instituições a saírem do ensino tradicional, em que o professor é o centro, para uma aprendizagem mais participativa e integrada [...]”.

Com sua linguagem própria, a matemática tem suas peculiaridades, logo espera-se do professor que ele dê ao aluno uma suavização ao ensinar tal habilidade, evitando mudanças bruscas no ensino, objetivando assim que haja uma melhor ensino-aprendizagem. E em qualquer sala é evidente que um assunto abstrato, quando tratado de uma forma mais fácil de se compreender, terá bons efeitos na aprendizagem dos alunos. Afinal, não há como ensinar inglês em um curto prazo de tempo e a pessoa compreender a língua inglesa, assim também a linguagem matemática é complexa, e leva-se tempo para que o aluno possa tomar aquele conhecimento para ele, pois há a necessidade de compreensão, e quando o professor busca uma metodologia de fácil compreensão para o mesmo, ele desenvolve até mesmo interesse pelas aulas, e pela disciplina, algo que hoje vem se perdendo aos poucos.

Os Parâmetros Curriculares Nacionais (PCN), (BRASIL, 1998), discorrem que o uso das tecnologias como recurso pedagógico possibilita que o aluno aprimore suas competências e habilidades, tanto nas práticas pedagógicas como também no mercado de trabalho. Ainda, assomam que as novas tecnologias trazem deveras, contribuições muito significativas, benefícios suficientes para se repensar no processo de ensino e aprendizagem de Matemática à medida que essas tecnologias entram em consonância com a matemática e passam a auxiliar na construção do conhecimento.

Sobre a importância das tecnologias e as relações com a Matemática, (D’AMBRÓSIO, 1996, p. 13), comenta:

Ao longo da evolução da humanidade, Matemática e tecnologia se desenvolveram em íntima associação, numa relação que poderíamos dizer simbiótica. A tecnologia 
entendida como convergência do saber (ciência) e do fazer (técnica), e a matemática são intrínsecas à busca solidária do sobreviver e de transcender. A geração do conhecimento matemático não pode, portanto ser dissociada da tecnologia disponível.

Logo o uso de tecnologias como o Geogebra já se faz necessário nas escolas, já que ele instiga os alunos a participarem, pois eles passam a ter mais interesse quando se trata de tecnologias, e isso funciona como um atrativo para que haja compreensão do conteúdo. Nesse sentido, o Geogebra possui ferramentas que venham a facilitar o ensino de funções trigonométricas, possibilitando visualizar um determinado gráfico em diferentes contextos, este software pode-se transformar em um recurso didático pedagógico, cabendo a responsabilidade ao professor aplicá-lo de maneira correta, para que venha a alcançar seus objetivos na disciplina de modo criativo e contextualizado. Portanto, o programa pode ser um atrativo nas aulas, como recurso facilitador na compreensão da disciplina, tornando as mais atrativas aos alunos.

\section{Metodologia}

Para alcançar os objetivos da pesquisa tem-se como referencial metodológico a pesquisa qualitativa, pois melhor se adequa com os objetivos desse trabalho de pesquisa. Onde que para Minayo (2001):

A pesquisa qualitativa responde a questões muito particulares. Ela se preocupa, nas ciências sociais, com um nível de realidade que não pode ser quantificado. Ou seja, ela trabalha com o universo de significados, motivos, aspirações, crenças, valores e atitudes, o que corresponde a um espaço mais profundo das relações, dos processos e dos fenômenos que não podem ser reduzidos à operacionalização de variáveis. (p. 21 e 22)

Esta pesquisa é do tipo pesquisa-ação, para a coleta de dados foi verificado que o professor titular de Matemática já havia ministrando o conteúdo de funções trigonométricas, e com isso facilitasse na comparação dos alunos entre aulas tradicionais e aulas com o uso de tecnologias.

A pesquisa-ação, em outras palavras, abarca um processo empírico que compreende a identificação do problema dentro de um contexto social e/ou institucional, o levantamento de dados relativos ao problema e a análise e significação dos dados levantados pelos participantes. Além da identificação da necessidade de mudança e o levantamento de possíveis soluções, a pesquisa-ação intervém na prática, no sentido de provocar a transformação. Coloca-se, então, como uma importante ferramenta metodológica capaz de aliar teoria e prática, por meio de uma ação que visa à transformação de uma determinada realidade (KOERICH MS, 2009). 
Foi também utilizado computador, data show, um pincel e um apagador para uma explicação do conteúdo, e para apresentar o Geogebra, e no mesmo apresentar de forma dinâmica e interativa as funções trigonométricas.

Foi escolhido o Educandário Bonus como escola para a coleta de dados acerca da pesquisa, pela proximidade da escola, e pela mesma estar em funcionamento, enquanto outras escolas já estavam no período correspondente às férias. Os sujeitos pesquisados foram 25 alunos da $2^{\mathrm{a}}$ série do ensino médio, onde foi feita a apresentação do conteúdo de funções trigonométricas, assunto este já visto pelos alunos, porém desta vez utilizando o Geogebra como meio facilitador do ensino, objetivando a fixação do conteúdo para os alunos. Logo após, foise aplicado um questionário de 5 perguntas com o objetivo de alcançar de forma mais clara e concreta os objetivos da pesquisa.

Foi seguido um roteiro, ao qual foi construído no Geogebra o círculo trigonométrico a partir da origem e com raio igual a 1 , como na figura1.

figura 1: Círculo trigonométrico feito no Geogebra.

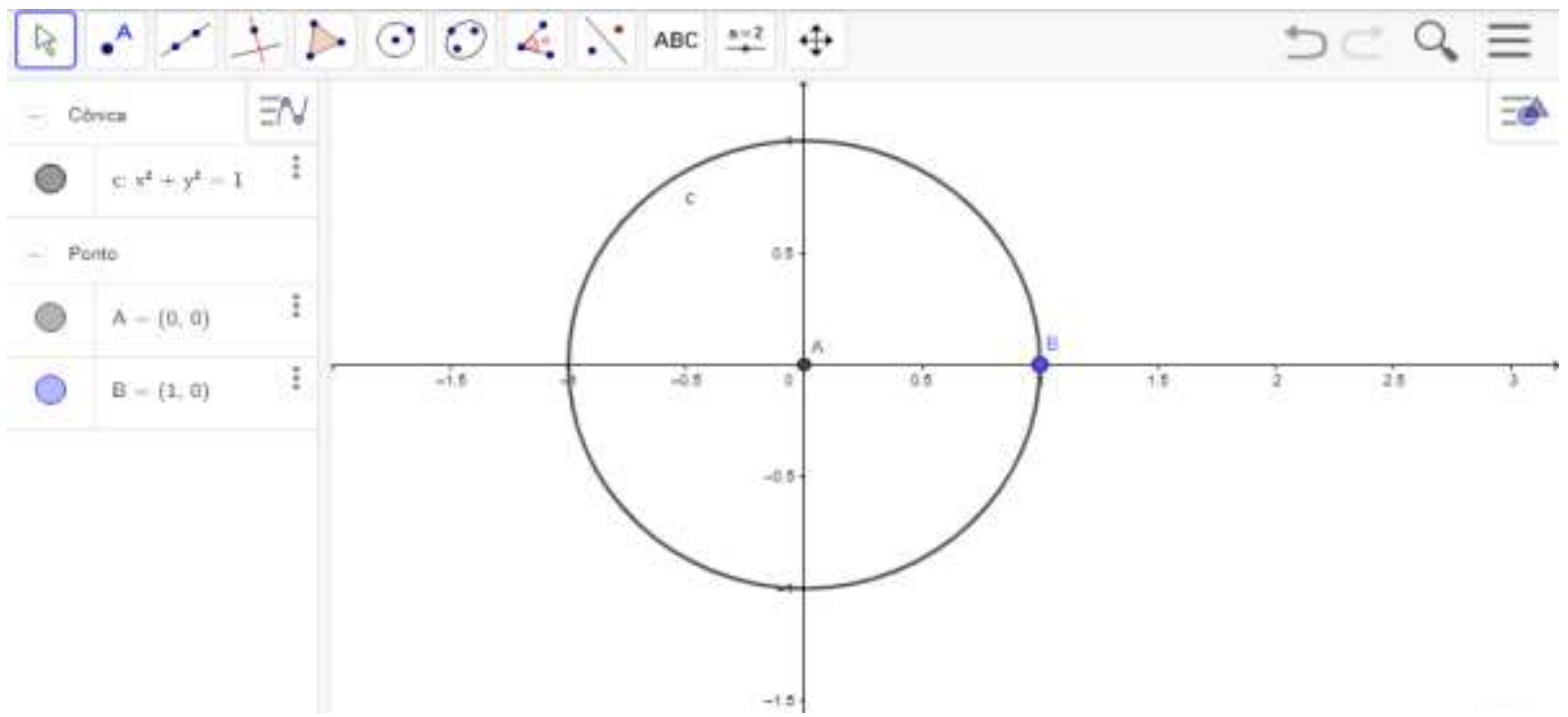

Fonte: Própria (2019)

Logo foi adicionado um ponto pertencente a circunferência, o ponto "C", um segmento de reta ligando a origem do plano ao ponto "C", e um ângulo "CÂB" que foi nomeado como ângulo " $\alpha$ ". Depois disso foi adicionado o ponto " $D$ " que pertencia ao eixo " $x$ " (eixo das abscissas) porém dependente de " $\mathrm{C}$ ”, digitando “( $\mathrm{C}(\mathrm{x}), 0)$ ” e pressionando "enter". Foi adicionado também o ponto "E" que pertencia ao eixo "y" (eixo das ordenadas) porém dependente de "C", digitando " $(0, \mathrm{C}(\mathrm{y}))$ " e pressionando "enter". Após isso, foi traçado uma reta perpendicular ao eixo " $\mathrm{x}$ " no ponto "B", que é a rata tangente. Depois adicionado um ponto "F", digitando na entrada " $(1, \operatorname{tg}(\alpha))$ ", $\log$ o o ponto " $F$ " seria dependente da abertura do ângulo 
“ $\alpha$ ". Com isso, 'poderia ser traçado segmentos pontilhados ligando “C” a " $\mathrm{D}$ ” e ligando também "C" a "E" no círculo que teriam relação ao seno e cosseno, e uma reta passando pela origem, "C" e "F" representando a tangente. E de forma interativa pode-se ver a questão dos valores de seno, cosseno e tangente e os sinais (+ e - ) dos quadrantes. Os pontos correspondentes aos ângulos que são mais comuns como os ângulos de $90^{\circ}, 180^{\circ}, 270^{\circ}$ e o $0^{\circ} / 360^{\circ}$, e seus respectivos valores de seno, cosseno e tangente, como representado na Figura 2.

Figura 2: Círculo trigonométrico feito no Geogebra, com as funções seno, cosseno e tangente.

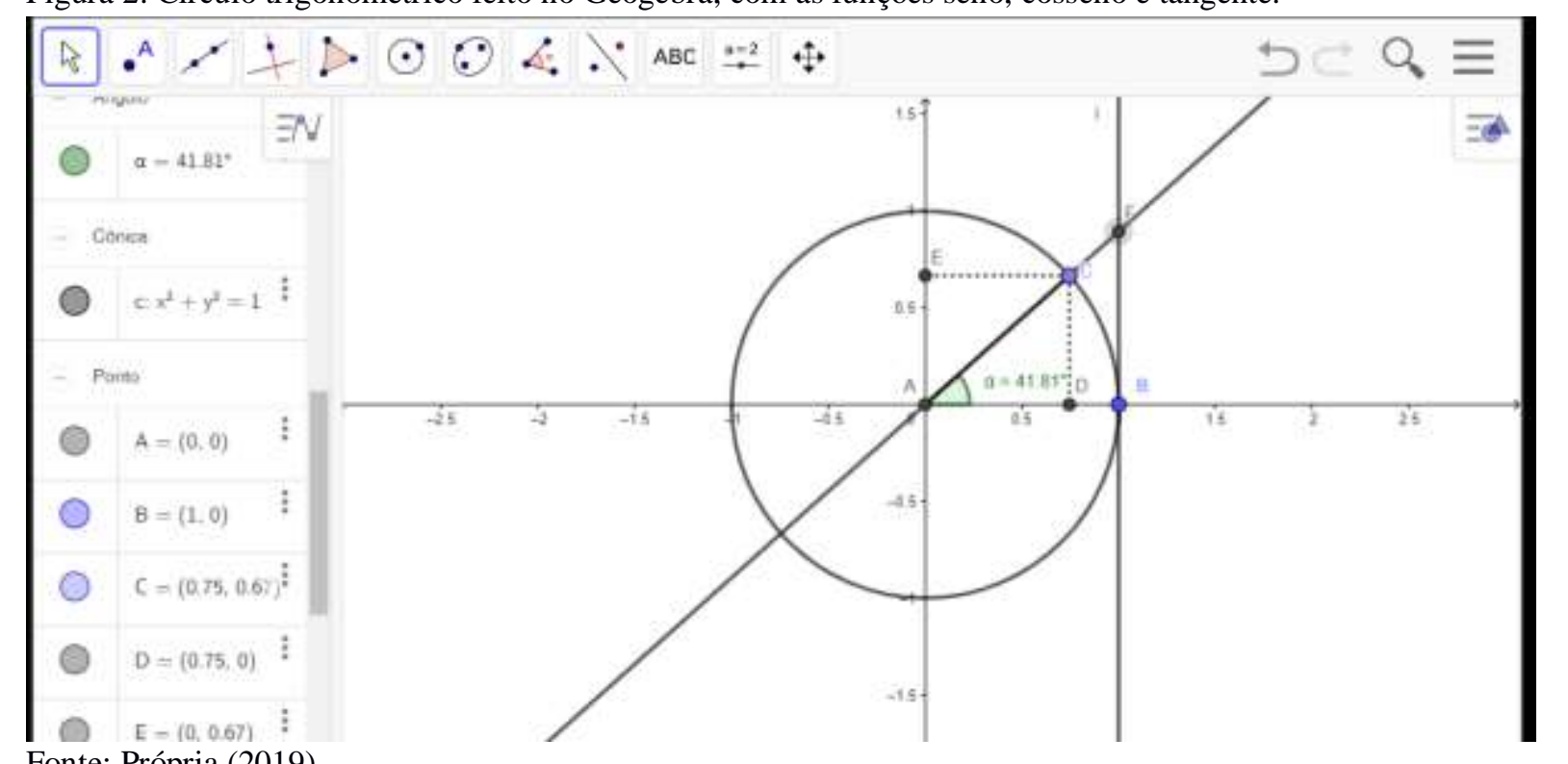

Fonte: Própria (2019)

\section{Resultados e Discussão}

A pesquisa foi realizada no Educandário Bonus, localizado na rua são pedro, $\mathrm{n}^{\circ}$ 96, no bairro Centro, na cidade de Água Branca-PI. A turma escolhida para a aplicação da pesquisa foi a $2^{\mathrm{a}}$ série do Ensino Médio, sendo composta por 25 alunos, com faixa etária de 15 a 16 anos de idade. Inicialmente, foi feita uma apresentação do que seria tratado com eles, e uma explicação sobre o que é a trigonometria e o que é o Geogebra, e como a trigonometria pode ser estudada usando este software.

Foi aplicado um questionário visando responder ao problema que movimentou esta pesquisa, e com a intenção de alcançar os objetivos da mesma. A primeira pergunta feita foi "Você já conhecia o Geogebra" e foi observado que a maioria não conhecia, como mostra o gráfico 1 a seguir: 
Gráfico 1: análise das respostas à $1^{\mathrm{a}}$ pergunta do questionário

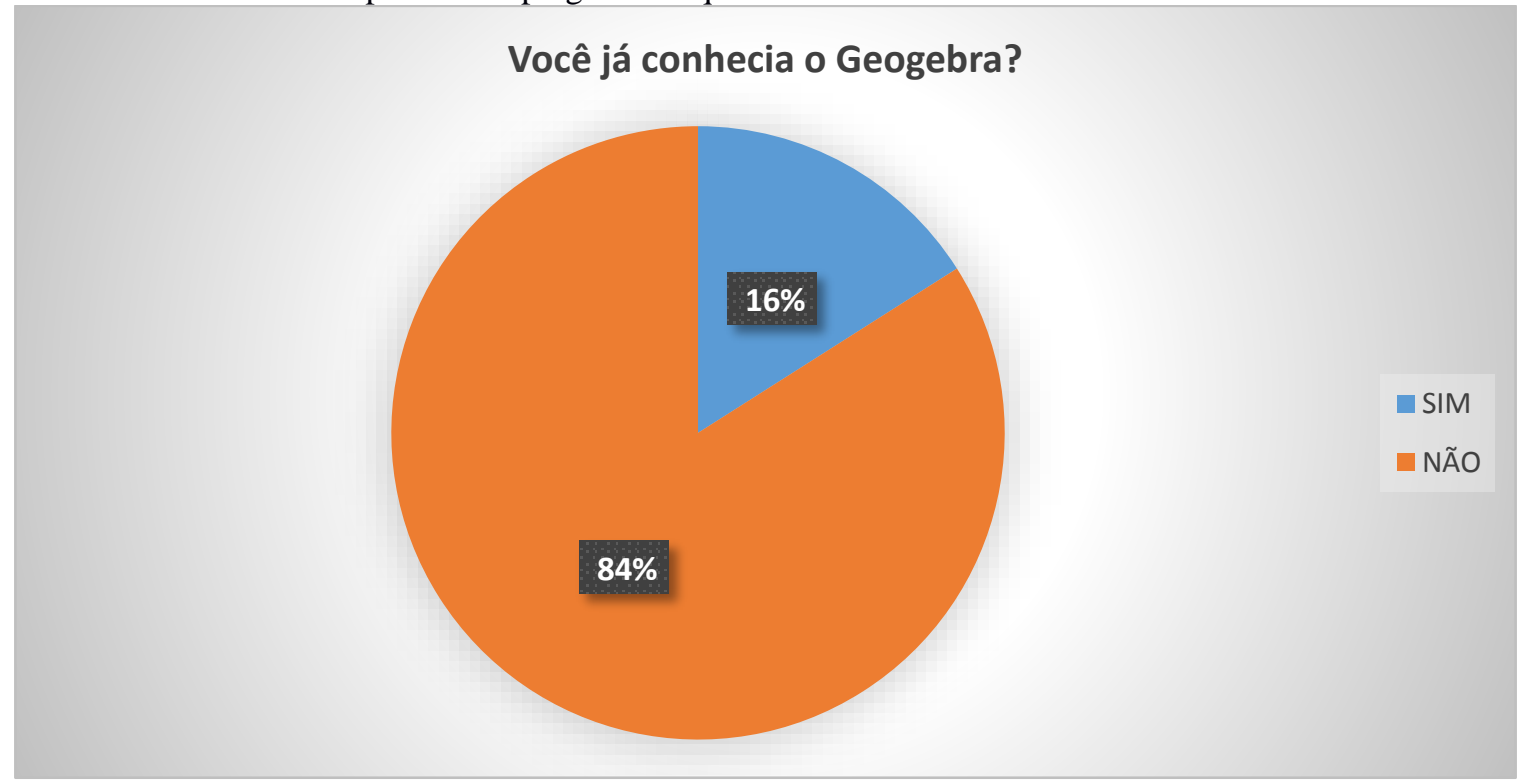

Fonte: Própria (2019)

Com isso observou-se que a maioria dos alunos, ainda não tinham entrado em contato com esse software tão importante para o ensino da matemática.

Na pergunta seguinte, "Ao ver a explicação de funções trigonométricas com o uso do Geogebra, você considera que absorveu mais conhecimento a respeito desse assunto?”, para se obter informações com relação a explicação dada a ele utilizando o software Geogebra, como é apresentado no gráfico 2:

Gráfico 2: análise das respostas à $2^{\mathrm{a}}$ pergunta do questionário

Ao ver a explicação de funções trigonométricas com o uso do geogebra, você considera que absorveu mais conhecimento a respeito desse assunto?

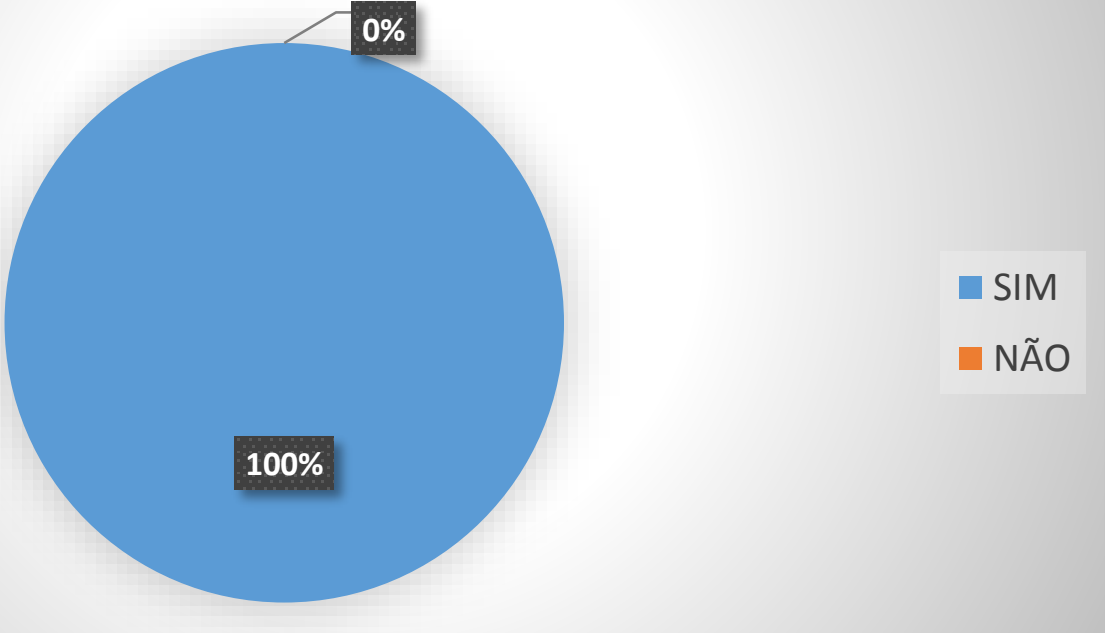

Fonte: Própria (2019) 
Como observado no gráfico, as respostas dos alunos foram afirmativas, mostrado assim que utilizando O Geogebra, os alunos compreenderam melhor o conteúdo, reafirmando assim que o uso das tecnologias em sala de aula para o ensino da matemática, deve ser considerado com necessário, principalmente se tratando de conteúdos em que o alunos deve visualizar o que o professor diz, para que haja melhor compreensão. o Geogebra possui ferramentas que vem a facilitar o ensino de funções trigonométricas, possibilitando a visualização de um determinado gráfico em diferentes contextos, este software pode-se transformar em um recurso didático pedagógico, cabendo a responsabilidade ao professor aplicá-lo de maneira correta, para que venha a alcançar seus objetivos na disciplina de modo criativo e contextualizado.

Foi perguntado aos alunos também: "Você considera esse tipo de aula necessário para que haja melhora no ensino?", e os mesmos responderam, de acordo com gráfico 3:

Gráfico 3: análise das respostas à $3^{\mathrm{a}}$ pergunta do questionário

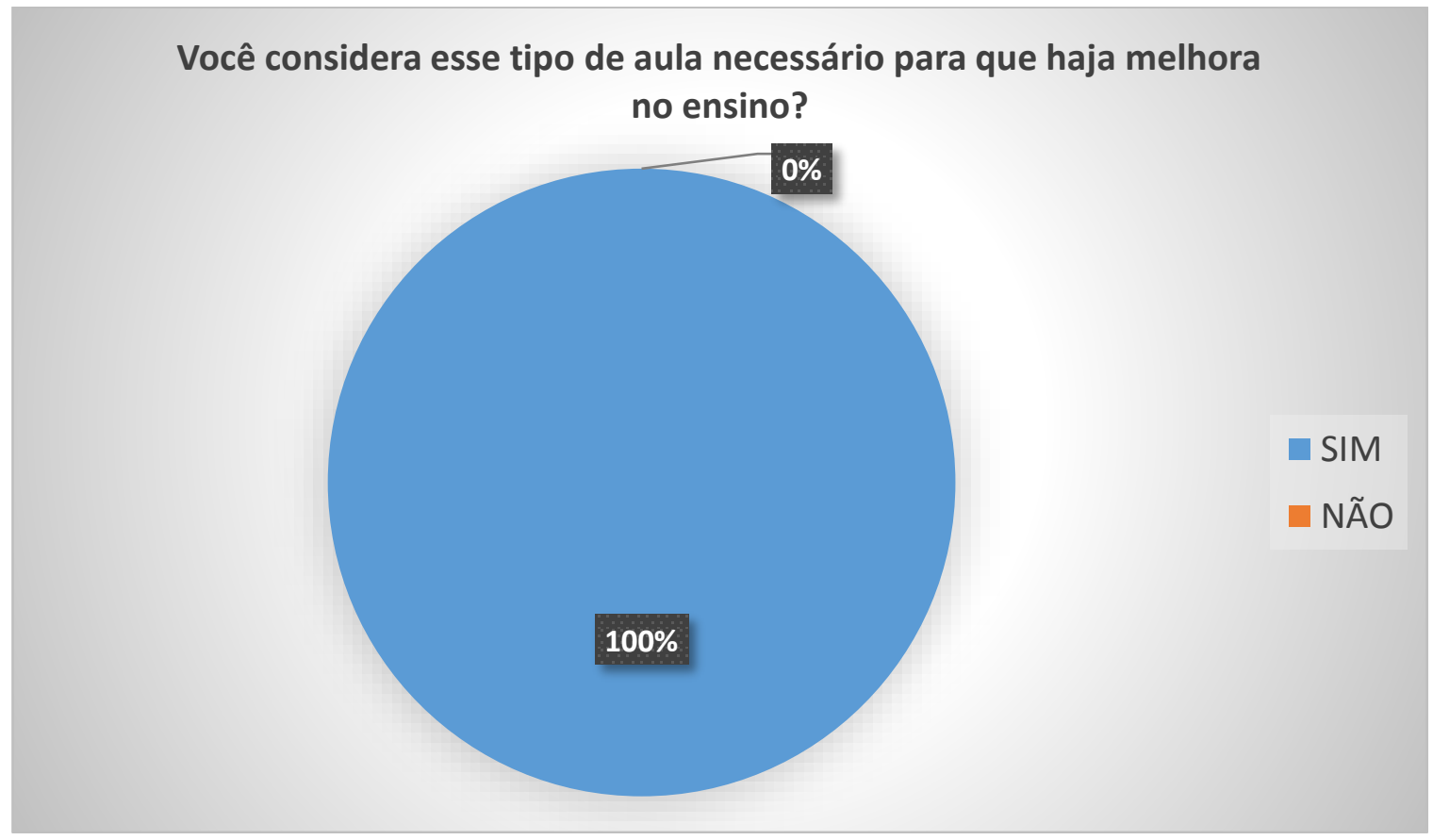

Fonte: Própria (2019)

A resposta afirmativa a esta pergunta mostra o devido interesse dos alunos com relação as tecnologias dentro de sala, pois o século em que vivemos as tecnologias estão em todas as partes, logo o ensino da matemática deve se desenvolver junto com as tecnologias, facilitando o ensino, e melhorando a aprendizagem.

Para a pergunta 4, "Como você encara o uso das novas tecnologias, como o Geogebra em sala de aula?", o sujeito 1 respondeu: "Pode ser uma ferramenta bastante útil para impulsionar o interesse dos alunos, principalmente, os que não gostam de matemática." 
Figura 6: foto da resposta do sujeito 1, à pergunta 4.

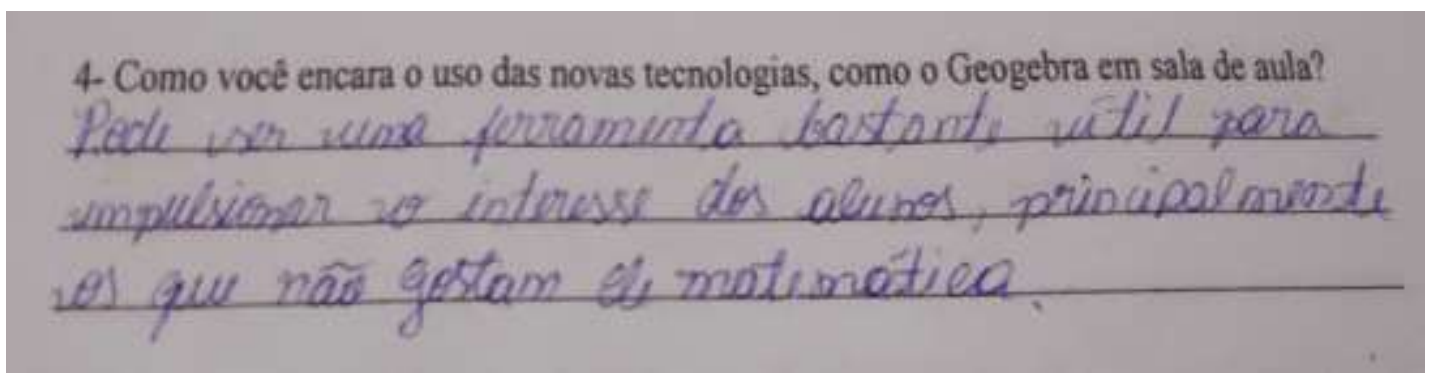

Fonte: Própria (2019)

O sujeito 2 disse: "Muito mais atrativo, onde chama atenção de todos e sei que tem bons resultados".

Figura 7: foto da resposta do sujeito 2, à pergunta 4.

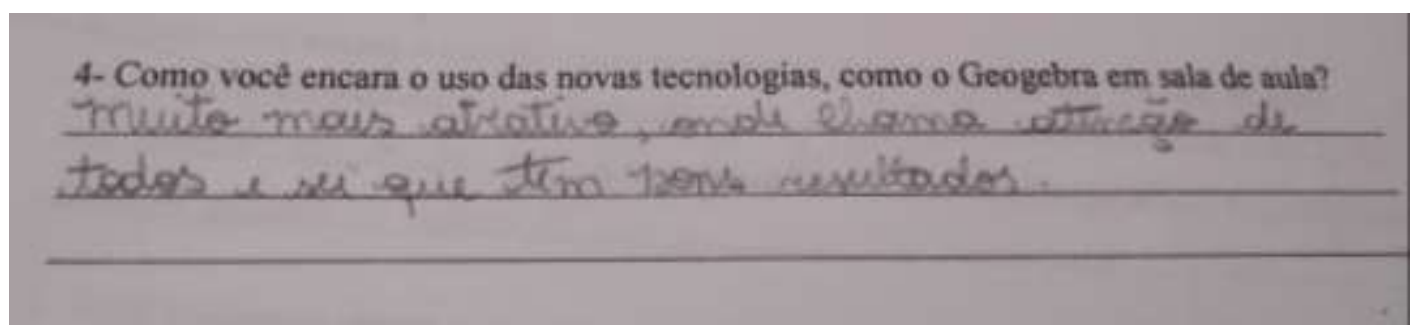

Fonte: Própria (2019)

O sujeito 3 disse: "É muito interessante, além de que o Geogebra abre mais a nossa mente para as figuras, facilitando tanto para o professor como para o aluno"

Figura 8: foto da resposta do sujeito 3, à pergunta 4.

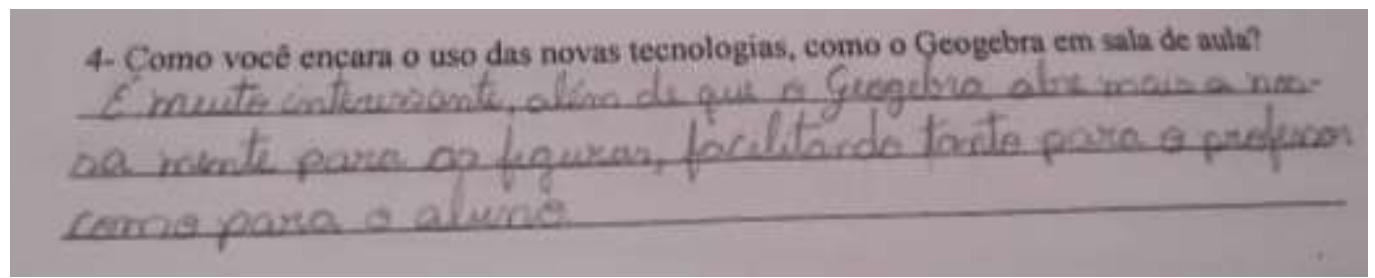

Fonte: Própria (2019)

O sujeito 4 disse: "Considero que com esses métodos a mente do estudante irá compreender melhor os conteúdos e terá melhor visualização deles, com isso seu aprendizado irá alcançar novas áreas e métodos de ensino"

Figura 9: foto da resposta do sujeito 4, à pergunta 4.

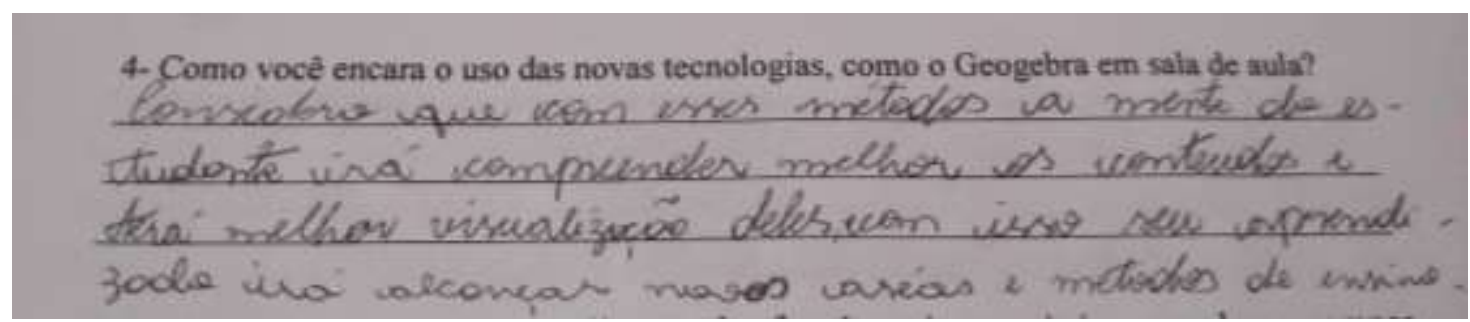

Fonte: Própria (2019) 
Todos os sujeitos responderam voltado para os benefícios do uso das tecnologias em sala de aula, pois a aula flui mais rápido, onde os mesmos percebem que o professor que dá aulas tradicionais acaba por não desenvolver por completo o interesse dos alunos, mas com as novas tecnologias, essas aulas chamam a atenção o aluno, e ele compreende melhor o conteúdo.

A pergunta 5, "Você conseguir observar a aplicação das funções trigonométricas em alguns campos importantes da nossa vida?", seria para que o mesmo refletisse sobre a palestra dada, e se o mesmo passou a ver a importância da trigonometria em sua vida, além de sua variada aplicabilidade.

Gráfico 4: analise das respostas à $5^{\mathrm{a}}$ pergunta do questionário

\section{Você conseguir observar a aplicação das funções trigonométricas em alguns campos importantes da nossa vida?}

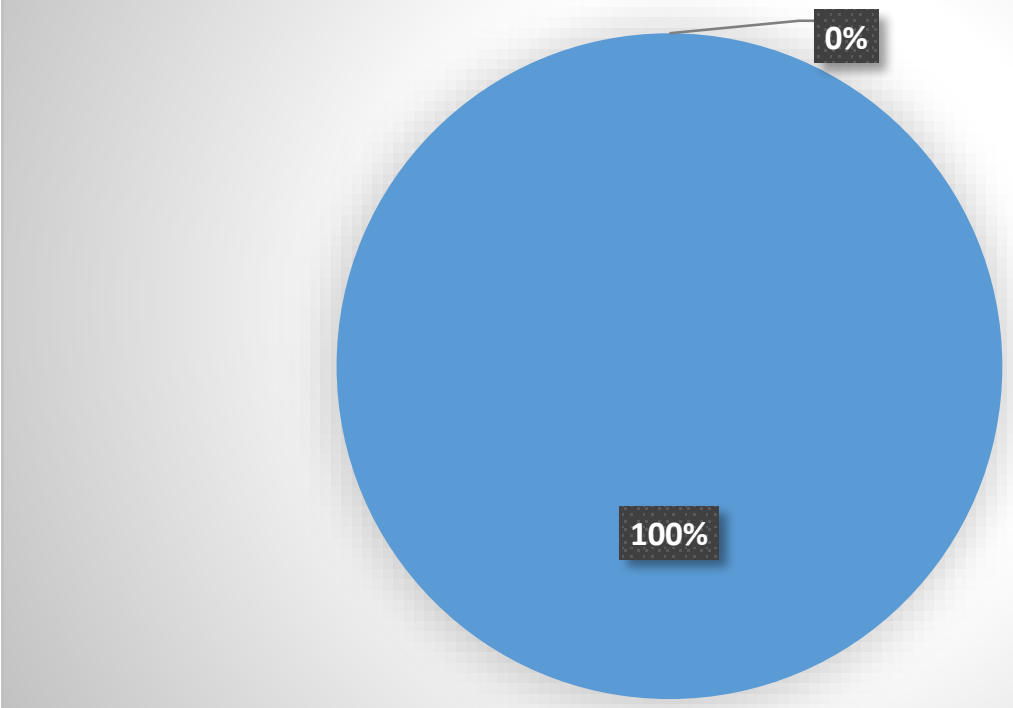

Fonte: Própria (2019)

Uma das maneiras de elevar o interesse do aluno é por mostrar com ele pode ver a presença daquele conteúdo no seu dia a dia, isso fará com que o mesmo desenvolva interesse pela matemática.

Com isso observamos que as aulas tradicionais se encontram em um patamar em que se deve repensar as práticas pedagógicas, novas metodologias de ensino, e com a inclusão cada vez mais dentro das escolas, das tecnologias, visando o professor utilizar para a melhoria do ensino da matemática. 


\section{Conclusões}

Nos nossos dias as ferramentas tecnológicas têm tido um crescimento exponencial. E o Geogebra demonstrou ser uma grande ferramenta tecnológica para ser utilizada em favor do ensino da matemática. Esta pesquisa feita no Educandário Bonus, mostrou que o Geogebra é foi eficaz no ensino de funções trigonométricas, mostrando assim que ferramentas tecnológicas, como o Geogebra, são necessárias e de grande importância para o ensino da matemática. A escola também possui um aparato tecnológico em favor dos professores o que facilita seu uso. Ao observar o comportamento e participação dos mesmos, pode-se afirmar que o Geogebra conseguiu captar a atenção dos mesmos, além de que os alunos também participaram, expondo opiniões e fazendo perguntas.

Captar a atenção dos alunos é o primeiro passo para a melhoria do ensino, e o Geogebra funcionou bem com relação a isso. Porem deve-se ressaltar que se não houver uma boa preparação por parte do professor, pode ocorrer de o mesmo ter uma experiencia ruim, e ao invés de poupar tempo e alcançar a aprendizagem dos alunos, pode a ocorrer o contrário.

Fica claro, que ministrar aulas sobre o uso do Geogebra como fora de capacitação dos professores é algo que é imprescindível, principalmente par aqueles que persistem em manter suas aulas $100 \%$ tradicionais. E como pesquisa futura, estudar as metodologias de ensino do professor de matemática da região, a fim de contribuir na melhoria do ensino. 


\section{Referências}

BRASIL. Secretaria de Educação Fundamental. Parâmetros curriculares nacionais: matemática. Secretaria de Educação Fundamental. - Brasília: MEC/SEF, 1997.

BRASIL. Ministério da Educação e do Desporto. Secretaria de Educação Fundamental. Parâmetros Curriculares Nacionais: Matemática (5ª a 8ª́ries). Brasília: MEC/SEF, 1998.

CARVALHO, Marcelo de Borba. GODOY, Miriam Penteado. Informática e Educação Matemática. -5. ed. - Belo Horizonte: Autêntica Editora, 2012.

CORRADI, D. K. S. Investigações matemáticas mediadas pelo pensamento reflexivo no ensino e aprendizagem das funções seno e cosseno: uma experiência com alunos do $2^{\circ}$ ano do Ensino Média. 2013. Dissertação (Mestrado em Educação Matemática) Universidade Federal de Ouro Preto.

D’ AMBRÓSIO, U. Educação matemática: da teoria à prática. 4 ed. São Paulo: Papirus, 1996.

FAZENDA, I. C. A. Interdisciplinaridade: um projeto em parceria. São Paulo: Edições Loyola, 2002. v. 13.

KOERICH, M. S; BACKES, D. S; SOUSA, F. G. M.; ERDMANN, A. L.; ALBUQUERQUE, G. L.. Pesquisa-ação: ferramenta metodológica para a pesquisa qualitativa. Revista Eletrônica de Enfermagem, 2009. Disponível em: 〈https://www.fen.ufg.br/revista/v11/n3/v11n3a33.htm>. Acesso em: 25 de julho de 2019.

MORAN, José Manuel; MASETTO, Marcos; BEHRENS, Marilda. Novas Tecnologias e Mediação Pedagógica. São Paulo: Papirus Editora, 2013.

PAIVA, M. Matemática. São Paulo: Moderna, 1997.

OLIVEIRA, F. C. d. Dificuldades no processo ensino aprendizagem de trigonometria por meio de atividades. Dissertação (Mestrado) — Universidade Federal do Rio Grande do Norte, 2006.

SILVA, Genilson Soares da. O USO DO GEOGEBRA NA COMPREENSÃO DE FUNÇÕES QUADRÁTICAS NO $1^{\circ}$ ANO DO ENSINO MÉDIO. Editora Realize. 2018. Disponível em: <https://www.editorarealize.com.br/revistas/conedu/trabalhos/TRABALHO EV117 MD1 S A13_ID7932_18082018170851.pdf >. Acesso em: 26 de julho de 2019. 
ANEXOS 


\section{ANEXO 1 \\ Questionário}

1-Você já conhecia o Geogebra?

( ) sim

( ) não

2- Ao ver a explicação de funções trigonométricas com o uso do Geogebra, você considera que absorveu mais conhecimento a respeito desse assunto?

( ) ( ) não

3- Você considera esse tipo de aula necessário para que haja melhora no ensino?

( ) $\operatorname{sim}$

( ) não

4- Como você encara o uso das novas tecnologias, como o Geogebra em sala de aula?

5- Você conseguir observar a aplicação das funções trigonométricas em alguns campos importantes da nossa vida?

( ) sim

( ) não 
ANEXO 2: Fotos da aula expositiva
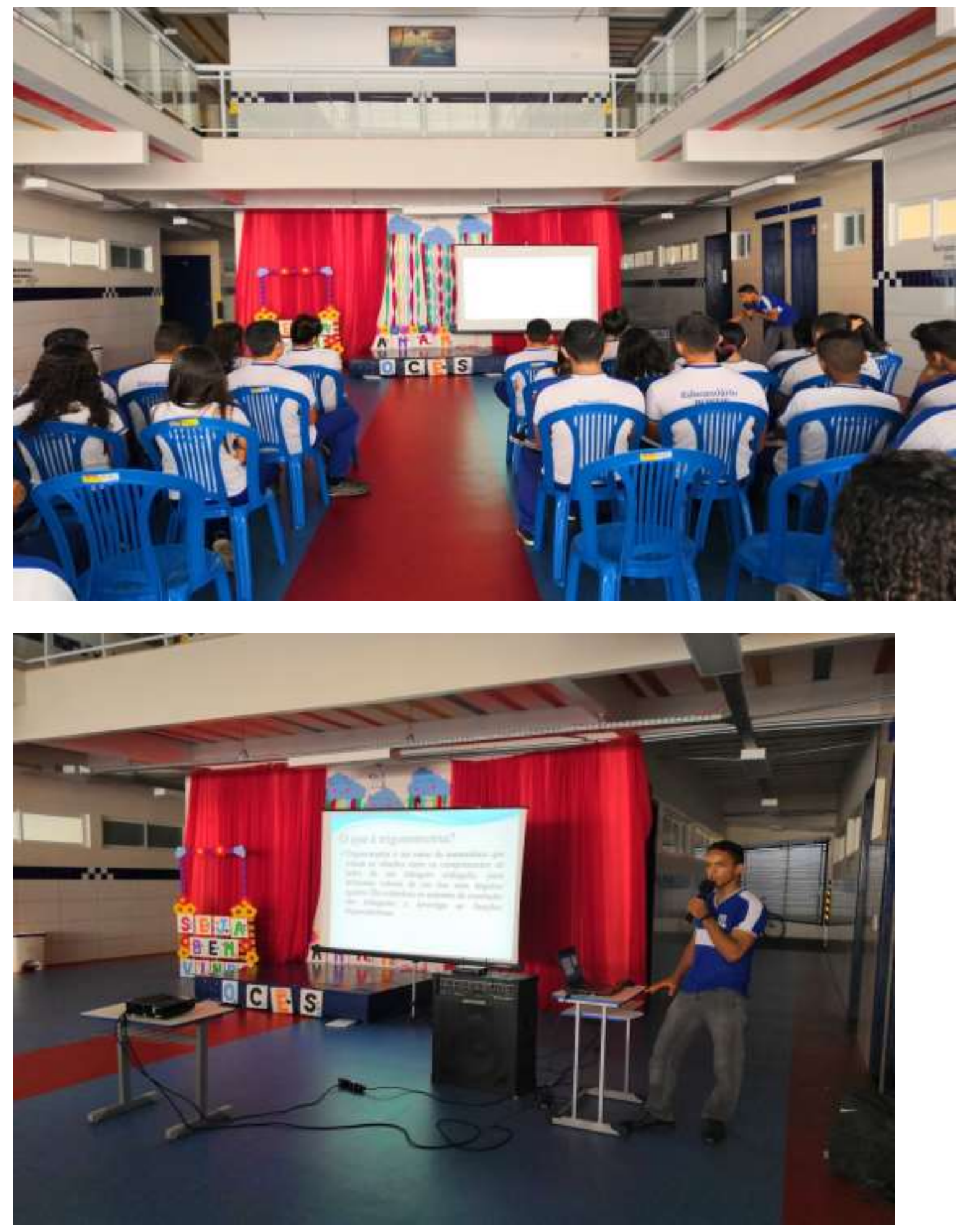


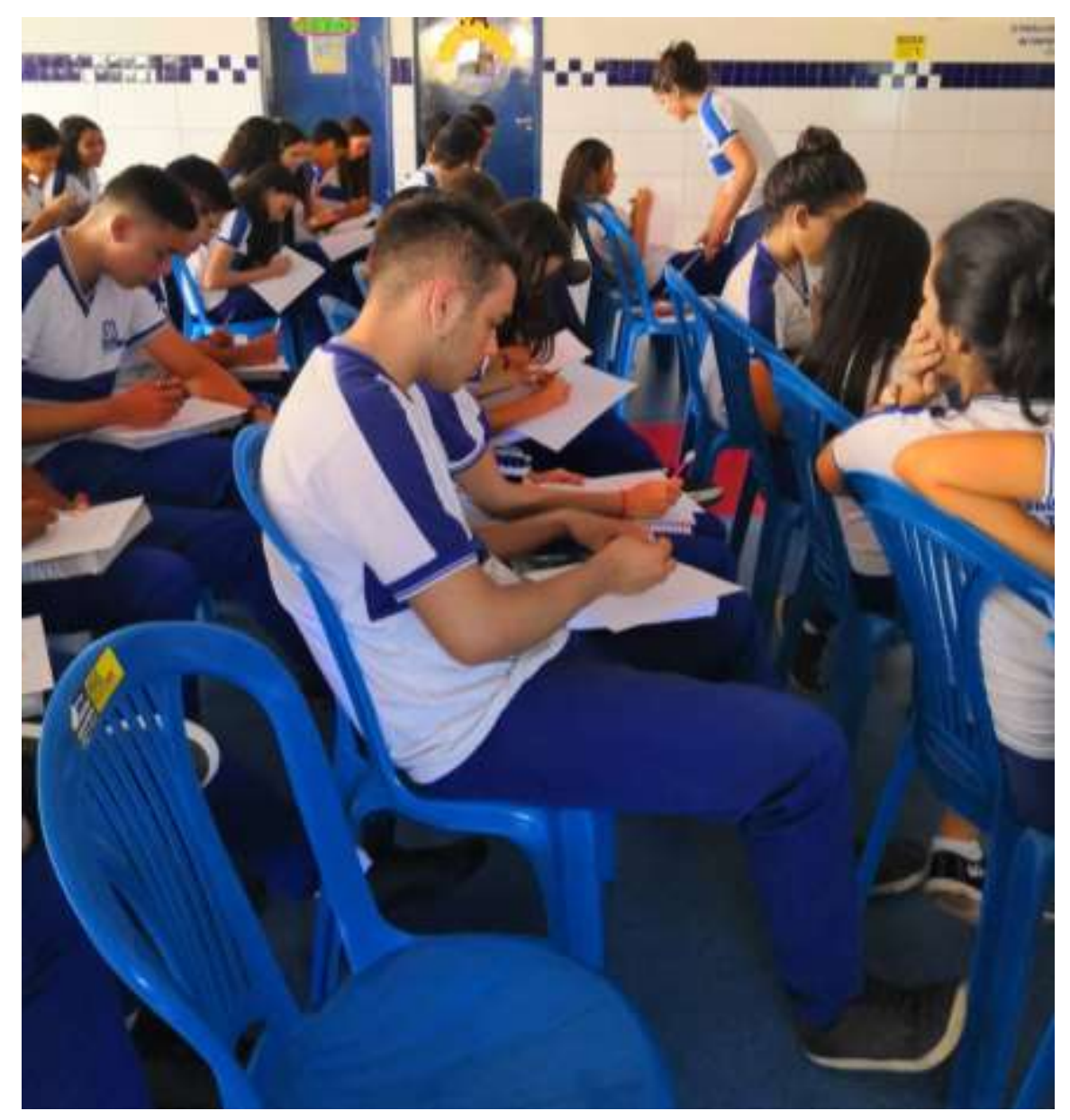

